\title{
The Relationship Between Gingivitis and the Serum Antibodies to the Microbiota Associated With Periodontal Disease in Children With Down's Syndrome
}

\author{
Takanobu Morinushi, ${ }^{*}$ Dennis E. Lopatin, ${ }^{\dagger}$ and Neal Van Poperin ${ }^{\dagger}$
}

GINGIVAL INFLAMMATION IN DOWN'S SYNDROME children (DS) develops earlier and is more rapid and extensive than in non-DS children. Abnormalities in host response to the oral flora have been proposed as etiological factors of this gingival inflammation. However, the relationship between gingivitis and the host response to oral microorganisms in DS by age has not been determined. The objective of this study was to clarify this relationship. Sera were obtained from 75 DS subjects (aged 2 to 18 years) and their gingival health assessed using a modified PMA Index (M-PMA). Antibody titers to Porphyromonas gingivalis ( $\mathrm{Pg}$ ), Prevotella intermedia (Pi), Treponema denticola (Td), Fusobacterium nucleatum (Fn), Selenomonas sputigena (Sel), Actinobacillus actinomycetemcomitans (Aa), and Streptococcus mitis (Mi) were determined using the micro-ELISA. DS subjects under 4 years old were found to have significantly more gingival inflammation than did normal children the same age. A significant positive correlation $(\mathrm{r}=0.548, P<0.0001)$ existed in the relationship between M-PMA score and plaque score for subjects in the G1 age group (deciduous dentition). At G1, the average antibody titers to $A a, M i$, and $F n$ exceeded those of the normal adult reference serum pool. In addition, IgG antibody titers to $\mathrm{Pg}, \mathrm{Aa}, \mathrm{Fn}$, Sel, and $M i$ correlated significantly with the M-PMA scores in the G1 age group. There was a correlation between age ( 2 to 18 years) and these antibody titers. IgG antibody titers to $\mathrm{Pg}, \mathrm{Aa}, \mathrm{Sel}$, and $\mathrm{Mi}$ increased significantly with increasing M-PMA score. Furthermore, the IgG antibody titers to $P g$ were higher $(P<0.05)$ in the most extensive disease group compared to the DS no-disease group. The IgG antibody titers to $P g$ at G3 (early puberty) were significantly higher when compared to G1 (preschool children). The IgM antibody titers to $A a$ at $\mathrm{G} 3$ were higher $(P<0.05)$ when compared to G1. This study suggests that colonization by $A a$ and $F n$ are closely associated with the onset of gingival inflammation in DS patients under 5 years old. Colonization by $P g, A a, S e l$, and $M i$ in DS appears to be associated with gingivitis at puberty. $J$ Periodontol 1997;68:626-631.

Key Words: Antibodies, bacterial; Down's syndrome; gingivitis/etiology; gingivitis/ microbiology.

Previous investigations of periodontal disease in children with Down's syndrome described a high prevalence of rapidly progressing extensive gingivitis. ${ }^{1-3}$ Gingival inflammation was reported to develop earlier and was more

*Department of Pediatric Dentistry, Kagoshima University Dental School, Kagoshima, Japan.

tDepartment of Biologic and Materials Sciences, School of Dentistry, University of Michigan, Ann Arbor, MI. rapid and extensive than in non-DS children. ${ }^{4}$ Abnormalities in systemic host defense mechanisms, including polymorphonuclear leukocyte chemotaxis and phagocytosis, have been proposed to contribute to the etiology of this rapidly progressive gingival inflammation. ${ }^{5-7}$

There are several studies of the microbiota and gingival inflammation in DS children. ${ }^{8-11}$ Among these, Meskin et al. ${ }^{8}$ implicated Bacteroides melaninogenicus as a possible 
Table 1. Number and Mean Age of Down's Syndrome Children by Hellman Dental Age (HDA) Category

\begin{tabular}{llrc}
\hline & & \multicolumn{2}{c}{ Dental Age } \\
\cline { 3 - 4 } HDA Category & Sex & N & Mean \\
\hline G1 & Male & 26 & 4.5 \\
& Female & 18 & 5.7 \\
G2 & Total & 44 & 5.0 \\
& Male & 4 & 7.3 \\
& Female & 4 & 7.5 \\
G3 & Total & 8 & 7.4 \\
& Male & 17 & 10.6 \\
& Female & 6 & 9.3 \\
& Total & 23 & 10.3 \\
\hline
\end{tabular}

The mean age of males $(n=47)$ is 7.0 years; of females $(n=28), 6.7$ years; of all children $(n=75), 6.9$ years.

etiological agent in periodontal disease, and Barr-Agholme et al. ${ }^{11}$ demonstrated an altered microbial composition of the subgingival plaque of Down's syndrome subjects compared to healthy controls, with a higher frequency of Actinobacillus actinomycetemcomitans in DS. However, the relationship between periodontal status, microbial colonization, and age has not been described. The purpose of this study was to establish the relationship between gingivitis and serum antibody titers to periodontal disease-associated microorganisms in children with Down's syndrome.

\section{MATERIALS AND METHODS}

\section{Subjects}

All protocols involving human subjects were approved by the Institutional Review Committee of Kagoshima University Dental School, and the study was performed in accordance with the Helsinki Declaration of 1975 , as revised in 1983. Seventy-five subjects (Table 1) living at home, aged 2 to 18 years, were recruited from a population of Down's syndrome children seen on an ongoing basis in the Kagoshima Prefectural Child Clinic and Guidance Center. Forty-four subjects had only a primary dentition. The definitive diagnosis of Down's syndrome (21 Trisomy) in these subjects was made by chromosomal examination.

\section{Gingival Health}

Gingival inflammation was assessed by a Modified Total PMA Index (M-PMA) of all sites based on the PMA Index of Massler. ${ }^{12}$ This index evaluates the number of gingival units (papillary, marginal, and attached gingiva) demonstrating gingival inflammation around erupted teeth and is limited to the anterior gingiva. Originally designed to survey large groups for epidemiologic studies, it is a useful index in the examination of children in whom later stages of periodontal disease are not usually observed. Plaque scores were evaluated by a single dentist using the Oral Hygiene Index by Greene and Vermillion. ${ }^{13}$

\section{Serum Specimens}

Five $\mathrm{ml}$ of blood was collected from the antecubital fossa into vacuum tubes without anticoagulants. After clotting, the sera were removed and stored at $-70^{\circ} \mathrm{C}$ until analyzed.

\section{Antigen Preparation}

Porphyromonas gingivalis (Pg, ATCC 33277), Prevotella intermedia (Pi, ATCC 33563), Treponema denticola ( $T d$, ATCC 35405), Fusobacterium nucleatum (Fn, ATCC 49256), Selenomonas sputigena (Sel, ATCC 43527), Actinobacillus actinomycetemcomitans (Aa, ATCC 43718 [Y4]) and Streptococcus mitis (Mi, ATCC 9811) were used as sources of antigen in this study. Five-hundred $\mathrm{ml}$ batches of these microorganisms were grown in Schaedler broth supplemented with $5 \mu \mathrm{g} / \mathrm{ml}$ of hemin and $1 \mu \mathrm{g} / \mathrm{ml}$ of menadione in an anaerobic chamber (85\% nitrogen, $10 \%$ hydrogen, and $5 \%$ carbon dioxide) at $37^{\circ} \mathrm{C}$. The microorganisms were harvested by centrifugation $(13,000 \times \mathrm{g})$ at late $\log$ phase in the presence of protease inhibitors (2mM EDTA, $0.5 \mathrm{mM}$ PMSF; $10^{-7} \mathrm{M}$ pepstatin A, $0.5 \mathrm{mg} / \mathrm{ml}$ leupeptin). The cell pellets were washed three times with phosphate buffered saline (PBS; 0.05 sodium phosphate, $0.15 \mathrm{M} \mathrm{NaCl}, \mathrm{pH}$ 7.4) containing 1mM EDTA and then fixed by incubation with $0.5 \%$ buffered formalin at room temperature for 16 to 18 hours on a rotary shaker. The formalinized bacteria were washed three times with PBS, then resuspended in distilled water and lyophilized.

\section{Antibody Measurements}

Semiquantitative measurements of the anti-bacterial antibodies in the sera of these subjects against the panel of seven microorganisms were performed using the microELISA; levels of antibody were expressed as ELISA units. $^{14,15}$ Briefly, formalinized microorganisms were diluted in $0.1 \mathrm{M}$ sodium carbonate buffer to a final concentration of 1 to $10 \mu \mathrm{g} / \mathrm{ml}$, dispensed into 96-well microtiter plates $(0.1 \mathrm{ml} /$ well $)$, and incubated for 2 hours at $37^{\circ} \mathrm{C}$. The plates were then stored at $4^{\circ} \mathrm{C}$ until used. Before use, the plates were washed with PBS containing $0.05 \%$ Tween-20 (PBS-T).

Serial dilutions of patient sera in PBS-T (beginning with 1:100 for IgG and 1:20 for IgM) were added to the wells and incubated for 1 hour at $37^{\circ} \mathrm{C}$. After washing with PBS-T, $0.1 \mathrm{ml}(1: 1,000$ dilution) of $\gamma$-chain or $\mu$-chain-specific goat anti-human immunoglobulin conjugated to alkaline phosphatase ${ }^{\ddagger}$ was added to each well and incubated for 1 hour at $37^{\circ} \mathrm{C}$. After a final wash, alkaline phosphatase substrate was added to each well, and the absorbance at $405 \mathrm{~nm}$ was measured using a multichannel spectrometer. A reference serum composed of a pool of 20 healthy adult sera possessing antibodies to all of the antigens used in this study was also titrated in each

${ }^{\ddagger}$ Zymed Laboratories, Inc., S. San Francisco, CA 
Table 2. The Prevalence of Gingival Inflammation in Down's Syndrome and Normal Children by Chronological Age Category

\begin{tabular}{|c|c|c|c|c|c|c|c|}
\hline \multirow{2}{*}{$\begin{array}{l}\text { Age Category } \\
\text { (Years) }\end{array}$} & \multirow[b]{2}{*}{ Mean Age } & \multicolumn{2}{|c|}{ Down's (DS) } & \multicolumn{3}{|c|}{ Normal (NC) } & \multirow[b]{2}{*}{ Significance } \\
\hline & & (n) & $\%$ & Mean Age & (n) & $\%$ & \\
\hline$\overline{<4}$ & 2.9 & $(8)$ & 100.0 & 2.9 & (24) & 79.2 & $\mathrm{DS}>\mathrm{NC}, P<0.05^{*}$ \\
\hline$\geq 4$ and $<7$ & 5.0 & (32) & 93.8 & 5.6 & (50) & 96.0 & N.S. \\
\hline$\geq 7$ and $<10$ & 7.9 & (21) & 86.4 & 8.4 & (55) & 100.0 & N.S. \\
\hline$>10$ & 11.8 & (14) & 100.0 & 14.0 & $(171)$ & 98.2 & N.S. \\
\hline
\end{tabular}

*Significant difference.

plate to allow internal standardization and calculation of ELISA units (EU). ${ }^{14}$ This reference represented the normal adult antibody levels to the selected microorganisms. EUs were calculated by relating absorbance values from each experimental sample to the reference serum which was assigned a value of $100 \mathrm{EU}$.

\section{Statistical Analysis}

The relationship between the antibody titer to each microorganism and dental age was evaluated by Pearson's correlation coefficient and Fisher's protected least significant difference (PLSD). The differences in antibody titer stratified by extent of gingivitis were evaluated by Spearman's rank correlation. The subjects were divided into three groups based on their Hellman Dental Age: G1 (HDA IIA, deciduous dentition), G2 (HDA IIC), and G3 (HDA IIIA-IVA, mainly mixed dentition). ${ }^{16}$ The dental age better reflects biological development than does chronological age, especially in Down's syndrome in which tooth eruption is delayed compared to normal siblings. ${ }^{17}$ Also, the dental age allows a better definition of the relationship between tooth eruption (i.e., deciduous and permanent teeth) and microbial/immunological measurements. The associations of M-PMA and antibody titer with age were examined, and the relationships between M-PMA and plaque score and antibody titer by all subjects and by HDA categories were also determined by regression analysis. In addition, the differences in M-PMA stratified by HDA categories were examined. All statistical analyses were performed on a computer using a statistical software program. ${ }^{\S}$

\section{RESULTS}

\section{Clinical Measurements}

The prevalence of gingival inflammation in Down's syndrome in various dental age groups was as follows: $<4$ years, $100 \%$; between 4 and 7 years, $93.8 \%$; from 7 years to $<10$ years, $86.4 \%$; $>10$ years, $100 \%$. A comparison of the prevalence of gingival inflammation in 75 DS versus 300 healthy non-DS children (177 males and $123 \mathrm{fe}-$ males) living in the same region is shown in Table 2 (data

\$StatView, Abacus Concepts, Inc., Berkeley, CA.
Table 3. Mean Antibody Titers by Hellman Dental Age of Down's Syndrome Children

\begin{tabular}{|c|c|c|c|}
\hline Antigen & HDA & $\begin{array}{c}\operatorname{IgG} \\
\text { Mean } \pm \mathrm{SD}\end{array}$ & $\begin{array}{c}\text { IgM } \\
\text { Mean } \pm \text { SD }\end{array}$ \\
\hline \multirow[t]{3}{*}{$\mathrm{Pg}$} & G1 & $77.6 \pm 43.4$ & $49.3 \pm 31.5$ \\
\hline & G2 & $105.3 \pm 147.5$ & $36.8 \pm 11.2$ \\
\hline & G3 & $173.9 \pm 219.5$ & $43.7 \pm 29.7$ \\
\hline \multirow[t]{3}{*}{$A a$} & G1 & $234.3 \pm 281.9$ & $49.1 \pm 29.5$ \\
\hline & G2 & $202.2 \pm 107.6$ & $68.8 \pm 23.6$ \\
\hline & G3 & $346.0 \pm 392.3$ & $47.4 \pm 18.7$ \\
\hline \multirow[t]{3}{*}{$F n$} & G1 & $114.0 \pm 92.6$ & $45.2 \pm 29.4$ \\
\hline & G2 & $118.2 \pm 70.3$ & $58.7 \pm 30.2$ \\
\hline & G3 & $117.8 \pm 79.6$ & $43.0 \pm 32.6$ \\
\hline \multirow[t]{3}{*}{$P i$} & G1 & $100.5 \pm 55.4$ & $42.5 \pm 38.6$ \\
\hline & G2 & $95.5 \pm 73.0$ & $53.0 \pm 31.5$ \\
\hline & G3 & $118.5 \pm 65.8$ & $38.3 \pm 20.0$ \\
\hline \multirow[t]{3}{*}{ Sel } & G1 & $71.7 \pm 38.9$ & $23.7 \pm 15.6$ \\
\hline & G2 & $70.2 \pm 75.2$ & $28.1 \pm 16.1$ \\
\hline & G3 & $82.1 \pm 64.4$ & $28.0 \pm 13.6$ \\
\hline \multirow[t]{3}{*}{$T d$} & G1 & $70.5 \pm 43.2$ & $30.4 \pm 19.4$ \\
\hline & G2 & $65.7 \pm 73.7$ & $30.3 \pm 9.5$ \\
\hline & G3 & $66.5 \pm 43.4$ & $38.5 \pm 22.9$ \\
\hline \multirow[t]{3}{*}{$M i$} & G1 & $179.4 \pm 120.5$ & $54.0 \pm 30.1$ \\
\hline & G2 & $164.4 \pm 110.5$ & $62.1 \pm 24.0$ \\
\hline & G3 & $206.8 \pm 160.4$ & $51.6 \pm 20.4$ \\
\hline
\end{tabular}

from Morinushi and Ueda, unpublished). As shown, the prevalence of gingival inflammation in DS under 4 years was significantly $(P<0.05)$ higher than that found in normal children.

In the present study, a significant positive correlation ( $\mathrm{r}=0.548, P<0.0001$ ) existed between the M-PMA score and plaque score for G1 subjects (deciduous dentition). M-PMA increased significantly $(\mathrm{r}=0.397, P<$ 0.001 ) with chronological age (all DS children). When compared by dental age categories, the average M-PMA score at G3 was higher than at G1, but was not significant $(P=0.097)$.

\section{Antibacterial Antibody Titers}

Serum samples obtained from the DS children were examined for the presence of $\operatorname{IgG}$ and IgM antibodies to the panel of seven oral microorganisms. The relationship between antibody titers and dental age category is shown in Table 3. At G1, the average antibody titer to $A a, M i$, and $F n$ exceeded that of the normal adult reference serum pool (100 EU). The mean IgG antibody titers to $P g$ at G3 (HDA classification corresponding to early puberty) were 
Table 4. Relationship Between Antibody Titer and Gingival Inflammation in Down's Syndrome Children

\begin{tabular}{|c|c|c|c|c|c|c|}
\hline \multirow{2}{*}{\multicolumn{2}{|c|}{ Antigen }} & \multicolumn{5}{|c|}{$\begin{array}{l}\text { Gingival Inflammation (M-PMA Score) } \\
\text { (n) }\end{array}$} \\
\hline & & $\begin{array}{c}0 \\
(6) \\
\text { Mean } \pm \text { SD }\end{array}$ & $\begin{array}{c}0<\text { and }<30 \\
(27) \\
\text { Mean } \pm S D\end{array}$ & $\begin{array}{c}30 \leq \text { and }<60 \\
(21) \\
\text { Mean } \pm \text { SD }\end{array}$ & $\begin{array}{c}60 \leq \text { and }<90 \\
(15) \\
\text { Mean } \pm S D\end{array}$ & \multirow{2}{*}{$\begin{array}{c}\geq 90 \\
(6) \\
\text { Mean } \pm \text { SD }\end{array}$} \\
\hline \multirow[t]{2}{*}{$P g$} & IgG & $62.1 \pm 37.9$ & $104.3 \pm 154.9$ & $115.3 \pm 123.5$ & $84.5 \pm 47.2$ & \\
\hline & IgM & $44.1 \pm 31.9$ & $54.1 \pm 33.4$ & $43.3 \pm 30.8$ & $40.7 \pm 19.4$ & $37.3 \pm 24.2$ \\
\hline \multirow[t]{2}{*}{$A a$} & IgG & $168.6 \pm 55.6$ & $250.2 \pm 347.0$ & $262.5 \pm 229.7$ & $278.9 \pm 213.1$ & $403.3 \pm 646.3$ \\
\hline & IgM & $50.1 \pm 28.9$ & $51.1 \pm 23.0$ & $47.1 \pm 32.9$ & $58.0 \pm 23.5$ & $44.1 \pm 24.6$ \\
\hline \multirow[t]{2}{*}{$F n$} & IgG & $63.5 \pm 22.7$ & $117.2 \pm 106.2$ & $124.7 \pm 61.6$ & $115.5 \pm 73.0$ & $128.6 \pm 124.0$ \\
\hline & IgM & $55.3 \pm 35.6$ & $50.9 \pm 32.7$ & $37.9 \pm 26.5$ & $48.0 \pm 31.6$ & $37.5 \pm 25.0$ \\
\hline \multirow[t]{2}{*}{$P i$} & IgG & $118.0 \pm 95.6$ & $84.4 \pm 35.6$ & $114.2 \pm 74.3$ & $117.8 \pm 51.8$ & $126.3 \pm 69.0$ \\
\hline & IgM & $28.3 \pm 18.5$ & $39.7 \pm 22.5$ & $50.0 \pm 44.8$ & $46.3 \pm 38.9$ & $31.7 \pm 14.7$ \\
\hline \multirow[t]{2}{*}{ Sel } & $\operatorname{IgG}$ & $75.9 \pm 37.5$ & $65.0 \pm 38.1$ & $82.0 \pm 64.1$ & $66.9 \pm 25.1$ & $110.0 \pm 99.7$ \\
\hline & IgM & $19.6 \pm 16.0$ & $28.6 \pm 16.5$ & $22.8 \pm 15.3$ & $25.0 \pm 10.2$ & $27.7 \pm 17.3$ \\
\hline \multirow[t]{2}{*}{$T d$} & IgG & $40.0 \pm 23.6$ & $68.8 \pm$ & $82.9 \pm 58.5$ & $57.2 \pm 26.6$ & $76.7 \pm 52.0$ \\
\hline & IgM & $31.0 \pm 22.8$ & $36.7 \pm 21.5$ & $26.9 \pm 16.3$ & $29.2 \pm$ & $47.3 \pm 33.7$ \\
\hline \multirow[t]{2}{*}{$M i$} & IgG & $149.3 \pm 136.5$ & $165.0 \pm 90.7$ & $181.5 \pm 95.8$ & $223.3 \pm 161.7$ & $242.0 \pm 273.6$ \\
\hline & IgM & $49.6 \pm 30.9$ & $55.0 \pm 22.3$ & $55.7 \pm 30.5$ & $56.1 \pm 30.5$ & $44.5 \pm 22.5$ \\
\hline
\end{tabular}

Mean age \pm SD of each group: score $=0,6 \pm 1.67 ; 0<$ score $<30,6 \pm 2.50 ; 30 \leq$ score $<60,7.1 \pm 2.93 ; 60 \leq$ score $<90,7.3 \pm 3.28 ;$ score $\geq 90$, $10 \pm 5.02$.

*Significant difference compared to titers of individuals having an M-PMA score of "0" (first column).

significantly higher when compared to G1 (corresponding to preschool children). In addition, the mean IgG antibody titer to $A a$ at $\mathrm{G} 3$ was significantly $(P<0.05)$ higher when compared to $\mathrm{G} 1$ and $\mathrm{G} 2$.

When the relationship between the IgG antibody titer and chronological age in DS children was examined, we found that antibody titers to $P g(\mathrm{r}=0.429, P<0.01)$, $A a(\mathrm{r}=0.360, P<0.01), F n(\mathrm{r}=0.0 .278, P<0.02)$, Sel $(\mathrm{r}=0.279, P<0.02)$, and $M i(\mathrm{r}=0.320, P<0.01)$ increased significantly with age. When IgM titers were examined, an increase was observed only with $T d(\mathrm{r}=$ $0.295, P<0.01)$.

\section{Relationships Between Antibody Titer and M-PMA}

When the correlation between antibody titer and M-PMA score was examined in all DS subjects, IgG antibodies to $P g(\mathrm{r}=0.283, P<0.02), A a(\mathrm{r}=0.282, P<0.02)$, Sel $(\mathrm{r}=0.260, P<0.05)$, and $M i(\mathrm{r}=0.330, P<0.05)$ increased significantly with increasing M-PMA. When the DS subjects were stratified by dental age, we found a significant positive correlation between M-PMA and IgG antibody titers to $A a(\mathrm{r}=0.496, P<0.02), F n$ ( $\mathrm{r}=$ $0.569, P<0.01)$, Sel $(\mathrm{r}=0.567, P<0.01)$, and $M i(\mathrm{r}$ $=0666, P<0.01)$ in $\mathrm{G} 3$. In addition, plaque scores were highest in G3.

When the mean antibody titers, grouped by extent of gingival inflammation (M-PMA), were compared (Table 4), we found no significant differences in either the IgG or IgM antibody titers to any of the microorganisms (Spearman's rank correlation). However, the mean IgG antibody titer to $P g$ was significantly higher (Fisher's PLSD) in the most extensive disease category compared to the " 0 " category. The mean IgG antibody titers to $A a$ and $M i$ were also higher in the most extensive disease category compared to the other categories, but this difference was not found to be statistically significant (Fisher's PLSD).

\section{DISCUSSION}

Previous studies of normal subjects have demonstrated that the serum antibody responses to a number of oral microorganisms correlated to the severity of periodontal disease. ${ }^{18-30}$ Other studies have reported that serum antibody levels to periodontopathic microorganisms are elevated in subjects having gingivitis. ${ }^{23.27 .28}$ However, there is a paucity of data relating the antimicrobial serology of gingivitis to antibody response in children with Down's syndrome (DS), a population presenting with a high prevalence of rapidly progressing extensive gingivitis starting in childhood. ${ }^{1-3}$ In this light, the findings of our study are important since they begin to clarify the relationship between the microbiota and gingivitis associated with Down's syndrome.

We found that the prevalence and extent of gingival inflammation (as measured by M-PMA) in DS is significantly higher than in normal children under the age of 4 years. The higher prevalence and greater extent of gingival inflammation in DS under the age of 6 years, compared with normal children, confirms previous studies. ${ }^{31}$ The relationship is especially marked in G1, representing children below the age of 6 years. One possible explanation for this observation is that the early onset of gingival inflammation is due to the reported abnormalities of systemic host defense, ${ }^{5,6}$ perhaps resulting in earlier colonization by periodontopathic microorganisms.

Previous studies of DS in children aged 4 to 18 years did not evaluate periodontopathic microorganisms in subgingival plaque, nor did they examine serum antibodies 
to periodontopathic microorganisms. Of the few studies examining the incidence of periodontopathic microorganisms in DS children, Meskin et al. ${ }^{8}$ studied children ranging from ages 5 to 12 years presenting with extremes in periodontal pathology. They concluded that there was an association between the presence of black-pigmented Bacteroides (BPB) and the prevalence of periodontal disease in DS children. In another study, Cutress et al. ${ }^{10}$ were not able to detect significant differences in BPB counts when DS and subjects with mental retardation (aged 9 to 24 years) were compared. However, there was a significant difference in BPB counts between subjects living at home and those who were institutionalized. Barr-Agholme et al. ${ }^{11}$ reported that $A$. actinomycetemcomitans was present in the subgingival plaque of DS subjects at a significantly greater frequency than in healthy children. They explained the higher prevalence of $A$. actinomycetemcomitans among DS subjects based on similarities with Haemophilus influenzae, which is associated with respiratory infections in DS..$^{32}$ DS patients are infected early with $H$. influenzae, and since A. actinomycetemcomitans is related to some species of the Haemophilus genus, they hypothesized a generalized susceptibility to these species. However, this is an insufficient explanation for the high prevalence of rapid progression and extensive gingival inflammation starting in early childhood of DS. The temporal relationships involved in colonization by microorganisms associated with periodontal disease and the relationship between gingival inflammation and periodontopathic microorganisms require additional investigation.

Our observations of the changes in IgG and IgM antibody titers with age suggest that colonization levels of $P g$, $A a, F n, S e l, T d$, and $M i$ increase with age. We are unaware of studies examining changes in antibody titers in healthy children. However, previous studies of colonization indicate that the incidence of black-pigmented Bacteroides (Bacteroides melaninogenicus or Bacteroides intermedius) in the supragingival plaque of young children increases $15 \%$ to $40 \%$ over a 3 - to 6 -year period. ${ }^{32-35}$ In a study by Frisken et al. ${ }^{36}$ BPB species were detected in the subgingival plaque of $31 \%$ to $61 \%$ of children aged 5 to 7 years, but $P g$ was detected in only $1.6 \%$ of the children. $F n$ was detected in $62 \%$ of children and $A a$ detected in $3 \%$ to $33 \%$ of children the same age range (varies with method of isolation). $P g$ and $A a$ were not detected routinely in children under 3 years. Conversely, $F n$ was detectable within the first 1 to 6 months of life. ${ }^{37}$

Using antibody titer as a surrogate for microbial colonization, some information on the colonization by the seven microorganisms may be deduced. At G1 (preschool children), titers to $A a, M i$, and $F n$ were significantly higher than the adult pool, while the titer to $P i$ was almost the same. This suggests that $F n, A a, M i$, and $P i$ are probably present in significant numbers in G1 children. These trends are in agreement with the age-related colonization trends reported for non-DS children of children reviewed above.

The extent of gingivitis, as evaluated with the M-PMA, increased with age in this study. We observed that antibody titers to $P g(\operatorname{IgG})$ and $A a(\operatorname{IgM})$ were significantly elevated in the most diseased subjects. Similarly, at G3 (early puberty) these titers were significantly higher compared with G1 (preschool children) or G2. In addition, IgG antibody titers to $P g, A a, F n, S e l$, and $M i$ correlated significantly with M-PMA in the G1 age group.

Some caution regarding the use of antibody titers as a surrogate for microbiological colonization is warranted. Clearly, there is not necessarily a direct relation between titer and bacterial presence. A progressive age-related correlation with antibody titer might also reflect immunological maturation in the young child. However, at least in the G1 Down's children where the titers are significantly elevated, the differences are unlikely to be related to immunological maturity.

Our findings suggest that colonization by $A a$ and $F n$ is associated with the onset and extent of gingivitis in DS children under the age of 5 years. In contrast, studies of non-DS children indicate that $\mathrm{Pg}$ is closely associated with the extent of gingivitis at puberty, probably associated with changes in levels of sexual hormones such as estradiol. ${ }^{38-41} \mathrm{Sel}$ appears to be associated with deteriorating periodontal health (simple gingivitis to severe periodontitis), based on our findings and reports by Moore et al. ${ }^{42,43}$ Finally, colonization by $M i$ in DS children appears to correlate with the extent of gingivitis. This may be important based on the work of Nagata et al., ${ }^{44}$ which indicated that $M i$ may play a role in the colonization of the periodontal pocket by $\mathrm{Pg}$. We are aware that these associations need to be further evaluated and the actual presence of the microorganisms confirmed. However, this work represents the first attempt at establishing the differences between DS and non-DS children with regard to colonization by putative periodontal pathogens.

\section{Acknowledgments}

This work was supported in part by USPHS grant DE06998.

\section{REFERENCES}

1. Brown RH. A longitudinal study of periodontal disease in Down's syndrome. NZ Dent J 1978;74:137-144.

2. Saxen L, Aula S. Periodontal bone loss in patients with Down's syndrome. A follow-up study. J Periodontol 1982;53:158-162.

3. Modeer T, Barr M, Dahllof G. Periodontal disease in children with Down's syndrome. Scand J Dent Res 1990;98:228-234.

4. Wilkinson PC. Chemotaxis and Inflammation. Edinburgh: Churchill Livingston; 1974:61-77.

5. Bosam WR, van Dijk LJ, van der Weele L. Experimental gingivitis around deciduous teeth in children with Down's syndrome. J Clin Periodontol 1986;13:294-300.

6. Bosma WR, Maria TH, Van den Barselaar JS, et al. Nonspecific and 
specific immune responses in a child with Down's syndrome and her sibling. A case report. J Periodontol 1988;59:249-253.

7. Izumi Y, Sugiyama $O$, Shinozuka $T$, Yamazaki $T$, Ohyama $T$, Ishikawa I. Defective neutrophil chemotaxis in Down's syndrome patients and its relationship to periodontal destruction. $J$ Periodontol 1989;60:238-242.

8. Meskin LH, Farsht EM, Andersson DL. Prevalence of Bacteroides melaninogenicus in the gingival crevice area of institutionalized trisomy 21 and cerebral palsy patients and normal children. $J$ Periodontol 1968;39:326-328.

9. Eastcott A, Loutit MW. Aerobic bacteria in saliva of mongols. $N Z$ Dent J 1968;64:11-17.

10. Cutress TW, Brown RH, Guy EM. Occurrence of some bacterial species in the dental plaque of trisomic 21 (mongoloid), other mentally retarded, and normal subjects. NZ Dent $J$ 1970;66:153-161.

11. Barr-Agholme M, Dahllof G, Linder L, Modeer T. Actinobacillus actinomycetemcomitans, Capnocytophaga and Porphyromonas gingivalis in subgingival plaque of adolescents with Down's syndrome. Oral Microbiol Immunol 1992;7:244-248.

12. Massler M. The P-M-A index for the assessment of gingivitis. $J$ Periodontol 1967;38(Suppl):592-601.

13. Greene JC, Vermillion JR. The Oral Hygiene Index. A method for classifying oral hygiene status. J Am Dent Assoc 1960;61:172.

14. Ebersole JL, Taubman MA, Smith DJ, Socransky SS. Humoral immune responses and diagnosis of human periodontal disease. J Periodont Res 1982;17:478-480.

15. Morinushi T, Lopatin DE, Syed SA, Bacon G, Kowalski CJ, Loesche WL. Humoral immune response to selected subgingival plaque microorganisms in insulin-dependent diabetic children. $J$ Periodontol 1989;60:199-204.

16. Hellman M. An introduction to growth of the human face from infancy to adulthood. Int J Orthod 1932;18:777-798.

17. Orner G. Posteruptive tooth age in children with Down's Syndrome and their sibs. J Dent Res 1975;54:581-587.

18. Ebersole JL, Taubman MA, Smith DJ, Haffajee AD. Effect of subgingival scaling on systemic antibody responses to oral microorganisms. Infect Immun 1985;48:534-539.

19. Ebersole JL, Taubman MA, Smith DJ, Frey DE. Human immune responses to oral microorganisms: Patterns of systemic antibody levels to Bacteroides species. Infect Immun 1986;51:507-513.

20. Ebersole JL, Frey DE, Taubman MA, Haffajee AD, Socransky SS. Dynamics of systemic antibody responses in periodontal disease. $J$ Periodont Res 1987;22:184-186.

21. Ebersole JL, Taubman MA, Smith DJ, Frey DE, Haffajee AD, Socransky SS. Human serum antibody responses to oral microorganisms. IV. Correlation with homologous infection. Oral Microbiol Immunol 1987;2:53-59.

22. Mouton C, Hammond PG, Slots J, Genco RJ. Serum antibodies to oral Bacteroides asaccharolyticus (Bacteroides gingivalis): Relationship to age and periodontal disease. Infect Immun 1981;31:182-192.

23. Naito Y, Okuda K, Takazoe I, Watanabe H, Ishikawa I. The relationship between serum IgG levels to subgingival gram-negative bacteria and degree of periodontal destruction. J Dent Res 1985;64: 1306-1310.

24. Schenck K, Helgeland K, Tollefsen T. Antibodies against lipopolysaccharide from Bacteroides gingivalis before and after periodontal treatment. Scand J Dent Res 1987;95:112-118.

25. Schenck K, Porter SR, Tollefsen T, Johansen JR, Scully C. Serum levels of antibodies against Actinobacillus actinomycetemcomitans in various forms of human periodontitis. Acta Odontol Scand 1989;47:271-277.

26. Taubman MA, Ebersole JL, Smith DJ. Association between systemic and local antibody and periodontal diseases. In: Genco RJ, Mergenhagen SE, eds. Host-Parasite Interactions in Periodontal Diseases. Washington, DC: ASM Press; 1982:283-298.

27. Tolo K, Brandtzaeg P. Relation between periodontal disease activity and serum titers to oral bacteria. In: Genco RJ, Mergenhagen SE, eds. Host-Parasite Interactions in Periodontal Diseases. Washington, DC: ASM Press; 1982:270-282.

28. Tolo K, Schenck K. Activity of serum immunoglobulins G, A, and $\mathrm{M}$ to six anaerobic, oral bacteria in diagnosis of periodontitis. $J$ Periodont Res 1985;20:113-121.

29. Vincent JW, Falkler WA Jr., Cornett WC, Suzuki JB. Effect of periodontal therapy on specific antibody responses to suspected periodontopathogens. J Clin Periodontol 1987;14:412-417.

30. Vincent JW, Falkler WA Jr., Suzuki JB. Systemic antibody response of clinically characterized patients with antigens of Eubacterium brachy initially and following periodontal therapy. $J$ Periodontol 1986;57:625-631.

31. Bosma WR, van Dijk J. Periodontal disease in Down's syndrome: A review. J Clin Periodontol 1986;13:64-73.

32. Anderson LJ, Parker RA, Strikas RA, et al. Day-care center attendance and hospitalization for lower respiratory tract illness. Pediatrics 1988;82:300-308.

33. Bailit HL, Baldwin DC, Hunt EE Jr. The increasing prevalence of gingival Bacteroides melaninogenicus with age in children. Arch Oral Biol 1964;9:435-438.

34. De Araujo WC, Macdonald JB. The gingival crevice microbiota in five preschool children. Arch Oral Biol 1964;9:227-228.

35. Kelstrup J. The incidence of Bacteroides melaninogenicus in human gingival sulci and its prevalence in the oral cavity at different ages. Periodontics 1966;4:14-18.

36. Frisken KW, Tagg JR, Law AJ, Orr MB. Suspected periodontopathic microorganisms and their oral habitats in young children. Oral Microbiol Immunol 1987;2:60-64.

37. Frisken KW, Higgins T, Palmer JM. The incidence of periodontopathic microorganisms in young children. Oral Microbiol Immunol 1990;5:43-45.

38. Kornman KS, Loesche WJ. The subgingival microflora during pregnancy. J Periodont Res 1980;15:111-122.

39. Jensen $\mathbf{J}$, Liljemark W, Bloomquist C. The effect of female sex hormones on subgingival plaque. J Periodontol 1981;52:599-602.

40. Wojcicki CJ, Harper DS, Robinson PJ. Differences in periodontal disease-associated microorganisms of subgingival plaque in prepubertal, pubertal and postpubertal children. J Periodontol 1987;58: 219-223.

41. Mombelli A, Lang NP, Burgin WB, Gusberti FA. Microbial changes associated with the development of puberty gingivitis. $J$ Periodont Res 1990;25:331-338.

42. Moore WEC, Holdeman LV, Cato EP, et al. Bacteriology of experimental gingivitis in young adult humans. Infect Immun 1982;38: 651-667.

43. Moore WEC, Holdeman LV, Smibert RM, et al. Bacteriology of severe periodontitis in young adult humans. Infect Immun 1982;38: 1137-1148.

44. Nagata H, Murakami $Y$, Inoshita E, Shizukuishi S, Tsunemitsu A. Inhibitory effect of human plasma and saliva on co-aggregation between Bacteroides gingivalis and Streptococcus mitis. J Dent Res 1990;69:1476-1479.

Send reprint requests to: Dr. Takanobu Morinushi, Department of Pediatric Dentistry, Kagoshima University Dental School, 8-35-1 Sakuragaoka Kagoshima 890, Japan.

Accepted for publication December 3, 1996. 